\title{
Spironolactone and risk of upper gastrointestinal events: population based case-control study
}

\author{
Katia M C Verhamme, Georgio Mosis, Jeanne P Dieleman, Bruno H Ch Stricker, Miriam C J M Sturkenboom
}

\begin{abstract}
Objective To confirm and quantify any association between spironolactone and upper gastrointestinal bleeding and ulcers. Design Population based case-control study.

Setting A primary care information database in the Netherlands.

Participants All people on the database who were aged 18 or more between 1 January 1996 and 30 September 2003. Patients with a history of alcoholism or gastrointestinal cancer were excluded. Ten controls were matched to each case of gastroduodenal ulcer or upper gastrointestinal bleeding by age (year of birth), sex, and index date.

Main outcome measures The occurrence of an upper gastrointestinal event (bleeding or ulcers), adjusted for potential confounders with conditional logistic regression analysis.

Results Within the source population of 306645 patients, 523 cases of gastric or duodenal ulcer or upper gastrointestinal bleeding were identified and matched to 5230 controls. Current use of spironolactone was associated with a 2.7 -fold $(95 \%$ confidence interval 1.2 to 6.0 ) increased risk of a gastrointestinal event.

Conclusion The risk of gastroduodenal ulcers or upper gastrointestinal bleeding is significantly increased in patients using spironolactone.
\end{abstract}

\section{Introduction}

The incidence of upper gastrointestinal bleeding and ulcers is decreasing because of better treatment, but patients are still admitted to hospital because of these conditions. ${ }^{1}$ Well known risk factors for upper gastrointestinal bleeding and ulcers are age, previous upper gastrointestinal bleeding or ulcers, smoking, alcohol misuse, infection with Helicobacter pylori, and drugs such as non-steroidal anti-inflammatory drugs, corticosteroids, anticoagulants, and selective serotonine reuptake inhibitors. ${ }^{2}{ }^{3}$ Case reports indicate a possible association between spironolactone, an aldosterone receptor antagonist, and upper gastrointestinal bleeding and ulcers. ${ }^{45}$ One study found that spironolactone may inhibit the healing of ulcers. ${ }^{6}$ In that study, spironolactone was combined with carbenoxolone, an established ulcer healing drug, to prevent symptoms of pseudo-hyperaldosteronism, a common adverse effect of carbenoxolone. Ulcer healing was impaired in patients treated with spironolactone and carbenoxolone, but not in patients treated with loop diuretics and carbenoxolone. In another clinical trial, ulcer healing was impaired when amiloride, a potassium sparing diuretic, was added to carbenoxolone. ${ }^{7}$
The mechanism behind the association between spironolactone and upper gastrointestinal events is not well understood, and the association has never been quantified. We therefore conducted a case-control study in the general population to examine the association between spironolactone and upper gastrointestinal events (bleeding and ulcers).

\section{Patients and methods}

\section{Setting}

Our study was conducted within the integrated primary care information (IPCI) project in the Netherlands. This electronic database contains information on more than 500000 patients registered with 150 general practitioners. The demographic characteristics of this population are similar to those in the national registry held by the Central Bureau of Statistics (www.cbs.nl).

In the Dutch healthcare system, all people are registered with one general practitioner who acts as a gatekeeper for medical care and information. ${ }^{8}$ The electronic records contain coded and anonymous data on patient demographics, symptoms and diagnoses (using the International Classification for Primary Care and free text terminology), clinical findings, referrals, laboratory findings, and hospitalisations..$^{9} 10$ Summaries of hospital discharge letters or information from specialists are entered in a free text format and hard copies can be provided on request. Information on drug prescription comprises brand name, amount, strength, indication, prescribed daily dose, and the Anatomical Therapeutic Chemical classification code. ${ }^{11}$ General practitioners who participate in the IPCI project are not allowed to use paper based records. The system complies with European Union guidelines on the use of medical data for medical research and is valid for pharmacoepidemiological research. ${ }^{12}$

\section{Source population}

The source population comprised all people aged 18 or more with at least one year's valid database history (that is, the practice had been sending data to the IPCI database for at least one year and the patient had been registered with the general practitioner for at least one year). We needed this length of time to have sufficient background information on all participants. Follow-up started on 1 January 1996 or the date that one year of valid history was obtained, whichever was latest. We excluded patients with a history of alcohol misuse or gastric cancer. All participants were followed from study entry until the first event (gastric or duodenal ulcer or upper gastrointestinal bleeding), the end of the study period (September 2003), exclusion, transfer from the practice, or death, whichever occurred first. 


\section{Identification and validation of cases}

The primary outcome was upper gastrointestinal bleeding or a symptomatic peptic or duodenal ulcer. Cases were all people with an upper gastrointestinal event confirmed by endoscopy. We identified potential cases on the computerised records by searching for International Classification for Primary Care diagnoses of gastrointestinal bleeding (D14-16), duodenal ulcer (D85), or peptic ulcer (D86) and by free text searches on melaena, haematemesis, and ulcer. We excluded bleeding of oesophageal varices and Mallory Weiss bleeding. The computerised medical records of all potential cases were manually evaluated by two doctors to exclude false positive records and to assess the earliest date of onset of each of the events (index date). Each case was classified as definite (patient with an upper gastrointestinal event confirmed by endoscopy) or possible (patient with signs of an upper gastrointestinal event not confirmed by endoscopy), or was excluded. Doctors were blinded to exposure to drugs throughout the validation process.

\section{Controls}

Up to 10 controls were obtained for each case from the source population. Controls were followed up at the same time as the case and we matched them for sex, age (year of birth), and calendar date (index date).

\section{Definition of drug exposure}

We retrieved all prescriptions for aldosterone antagonists, loop diuretics, and amiloride before the index date. Exposure was classified as "current" if the last prescription covered the index date or ended within one month before the index date; exposure was "past" if the period covered by the last prescription ended between the start of our study and one month before the index date. We classified participants with no prescription within this period as non-users. For current users, we studied the effects of daily dose. Daily doses were expressed as defined daily dose equivalents.

\section{Covariates}

We considered the following conditions as potential confounders: a history of smoking, ischaemic heart disease (angina pectoris and myocardial infarction), stroke (cerebral bleeding, ischaemic events, and transient ischaemic attacks), peripheral artery disease, hypertension, diabetes mellitus, heart failure, previous upper gastrointestinal events (ulcers or bleeding), and previous gastritis or oesophagitis.

The following concomitant drugs were taken into account as covariates: non-steroidal anti-inflammatory drugs, systemic corticosteroids, platelet aggregation inhibitors (including acetylsalicylic acid), anticoagulants, antidepressants, proton pump inhibitors or histamine 2 receptor antagonists, antacids, and cardiovascular drugs (digoxin, angiotensin converting enzyme inhibitors, angiotensin II receptor antagonists, calcium channel blockers, $\alpha$ blockers, $\beta$ blockers, and other diuretics).

\section{Statistical analysis}

We calculated the incidence of upper gastrointestinal events and the incidence of first time use of spironolactone by dividing the number of upper gastrointestinal events and first time users of spironolactone by the number of person years accumulated by the study population.

We used conditional logistic regression analysis to assess the matched unadjusted and adjusted estimates of risk for the association between risk factors and upper gastrointestinal events and exposure to diuretics and the occurrence of an upper gastrointestinal event. In the adjusted model we included, one by one, all covariates that were univariately associated with outcome
$(\mathrm{P}<0.05)$. Risk factors that changed the relative risk of an upper gastrointestinal event during current use of diuretics by more than $5 \%$ were maintained in the final model.

To estimate the proportion of upper gastrointestinal events in the total population that can be attributed to current use of spironolactone, we calculated the population attributable risk (population attributable risk $=$ attributable risk $\times$ proportion exposed in the population). ${ }^{13}$ For this calculation, "attributable risk" was the incidence rate in the exposed population minus the incidence rate in the unexposed population, and the "proportion exposed" was the proportion of controls currently using spironolactone. Data from the Dutch Central Bureau of Statistics (www.cbs.nl) were used to extrapolate our results to the entire Dutch population of 18 years or more. We used SPSS 11.5 software for all analyses.

\section{Results}

Our source population consisted of 306645 patients who contributed 1003053 person years. We identified 523 definite upper gastrointestinal events (209 gastroduodenal ulcers and 314 cases of upper gastrointestinal bleeding) and 450 possible events, resulting in an overall incidence of 9.7 per 10000 person years. To avoid false positive misclassification of the outcome, we only included definite cases in our case-control analyses. For the 523 definite cases, we randomly selected 5230 controls, matched on index date, age, and sex. The mean age of the cases was 63.4 years (standard deviation 17.5). Cases had a higher prevalence of previous gastrointestinal bleeding, gastric and duodenal ulcers, oesophagitis, heart failure, and peripheral artery disease (table 1). Current use of non-steroidal anti-inflammatory drugs, corticosteroids, antacids, proton pump inhibitors or histamine 2 antagonists, anticoagulants, and platelet aggregation inhibitors was higher among cases than controls (table 1). A history of stroke, ischaemic heart disease, and smoking and current use of antidepressants, calcium channel blockers, angiotensin converting enzyme inhibitors, and nitrates were also associated with upper gastrointestinal bleeding or ulcers, but the association was smaller (odds ratio <2). During the study period 1717 patients started taking spironolactone for the first time. The incidence rate of first time use of spironolactone increased from 0.7 per 1000 person years in 1996 to 3.1 per 1000 person years in 2003 .

Current use of spironolactone was associated with a 2.7-fold increase $(95 \%$ confidence interval 1.2 to 6.0$)$ in upper gastrointestinal events (table 2). The association was strongest in patients taking the higher doses of the drug-a 5.1-fold increase (1.5 to 17.1) in upper gastrointestinal events was seen with current use of $\geq 0.5$ defined daily dose of spironolactone compared with no use (table 2). Increasing dosages of loop diuretics or amiloride were not associated with upper gastrointestinal bleeding (table 2).

Most patients used spironolactone for heart failure, but some used it for treatment of hypertension and one used it for liver cirrhosis. When we stratified patients into those with or without heart failure, an association was seen between current use of spironolactone and upper gastrointestinal events in patients without heart failure. However, when fully adjusted the association was not statistically significant because of the low numbers (adjusted odds ratio 4.0, 0.99 to 16.6).

We studied effect modification by ulcerogenic drugs such as non-steroidal anti-inflammatory drugs, platelet aggregation inhibitors, corticosteroids, and anticoagulants. As expected, the association with upper gastrointestinal events was highest for patients currently taking spironolactone and an ulcerogenic 
Table 1 Risk of upper gastrointestinal events according to patient characteristics. ${ }^{*}$ Values are numbers (\%) unless stated otherwise

\begin{tabular}{|c|c|c|c|}
\hline Characteristic & $\begin{array}{l}\text { Cases } \\
(n=523)\end{array}$ & $\begin{array}{l}\text { Controls } \\
(n=5230)\end{array}$ & $\begin{array}{l}\text { Adjusted odds ratio } \\
(95 \% \mathrm{Cl})\end{array}$ \\
\hline \multicolumn{4}{|l|}{ Comorbidity } \\
\hline $\begin{array}{l}\text { History of upper gastrointestinal } \\
\text { bleeding }\end{array}$ & $10(1.9)$ & $19(0.4)$ & 5.39 (2.48 to 11.7$)$ \\
\hline $\begin{array}{l}\text { History of gastric or duodenal } \\
\text { ulcer }\end{array}$ & $25(4.8)$ & $55(1.1)$ & 4.79 (2.95 to 7.80$)$ \\
\hline History of oesophagitis & $88(16.8)$ & $378(7.2)$ & 2.61 (2.02 to 3.36$)$ \\
\hline Heart failure & $53(10.1)$ & $246(4.7)$ & 2.54 (1.81 to 3.56$)$ \\
\hline Peripheral artery disease & $21(4.0)$ & $102(2.0)$ & 2.13 (1.31 to 3.46$)$ \\
\hline \multicolumn{4}{|l|}{ Current use of other drugs } \\
\hline $\begin{array}{l}\text { Non-steroidal anti-inflammatory } \\
\text { drugs }\end{array}$ & $75(14.3)$ & $261(5.0)$ & 3.32 (2.49 to 4.42$)$ \\
\hline Systemic corticosteroids & $22(4.2)$ & $61(1.2)$ & 3.91 (2.36 to 6.47$)$ \\
\hline Platelet aggregation inhibitors & $111(21.2)$ & $714(13.7)$ & 2.16 (1.68 to 2.78$)$ \\
\hline Anticoagulants & $26(5.0)$ & $132(2.5)$ & 2.16 (1.40 to 3.33$)$ \\
\hline $\begin{array}{l}\text { Proton pump inhibitors or } \\
\text { histamine } 2 \text { antagonists }\end{array}$ & $66(12.6)$ & $303(5.8)$ & 2.83 (2.11 to 3.78$)$ \\
\hline Antacids & $7(1.3)$ & $20(0.4)$ & 3.52 (1.49 to 8.33) \\
\hline Diuretics & $79(15.1)$ & $558(10.7)$ & 1.73 (1.31 to 2.94$)$ \\
\hline
\end{tabular}

*Only variables with an odds ratio $\geq 2$ shown, except for use of diuretics.

$\operatorname{drug}(7.3,2.9$ to 18.7 ; table 3$)$. Effect modification was not seen in patients taking loop diuretics and ulcerogenic drugs (table 3).

We saw no effect modification by sex or age. The duration of spironolactone use was not associated with outcome (data not shown).

Table 2 Risk of upper gastrointestinal events according to use of spironolactone, loop diuretics, and amiloride. Values are number (\%) unless stated otherwise

\begin{tabular}{|c|c|c|c|c|}
\hline & Cases $(n=523)$ & $\begin{array}{l}\text { Controls } \\
(n=5230)\end{array}$ & Odds ratio & $\begin{array}{l}\text { Adjusted odds } \\
\text { ratio* }(95 \% \mathrm{Cl})\end{array}$ \\
\hline \multicolumn{5}{|l|}{ Spironolactone } \\
\hline Never used & $506(96.7)$ & $5176(99.0)$ & 1.0 & 1.0 \\
\hline Currently used & $13(2.5)$ & $30(0.6)$ & 4.6 & 2.7 (1.2 to 6.0$)$ \\
\hline $\begin{array}{l}<0.5 \text { defined daily } \\
\text { dose }\end{array}$ & $7(1.3)$ & $21(0.4)$ & 3.5 & $1.9(0.7$ to 5.1$)$ \\
\hline $\begin{array}{l}\geq 0.5 \text { defined daily } \\
\text { dose }\end{array}$ & $6(1.1)$ & $9(0.2)$ & 7.3 & 5.1 (1.5 to 17.1$)$ \\
\hline Used in the past & $4(0.8)$ & $24(0.5)$ & 1.8 & 0.99 (0.3 to 3.1) \\
\hline \multicolumn{5}{|l|}{ Loop diuretics } \\
\hline Never used & $465(88.9)$ & $4906(93.8)$ & 1.0 & 1.0 \\
\hline Currently used & $31(5.9)$ & $157(3.0)$ & 2.2 & $1.2(0.7$ to 2.0$)$ \\
\hline $\begin{array}{l}<1 \text { defined daily } \\
\text { dose }\end{array}$ & $5(1.0)$ & $23(0.4)$ & 2.5 & 1.7 (0.6 to 4.8$)$ \\
\hline $\begin{array}{l}1 \text { defined daily } \\
\text { dose }\end{array}$ & $15(2.9)$ & $83(16)$ & 2.0 & 1.1 (0.6 to 2.2) \\
\hline $\begin{array}{l}>1 \text { defined daily } \\
\text { dose }\end{array}$ & $11(2.1)$ & $51(1.0)$ & 2.4 & 1.1 (0.5 to 2.4) \\
\hline Used in the past & $27(5.2)$ & $167(3.2)$ & 1.8 & 1.0 (0.6 to 1.7) \\
\hline \multicolumn{5}{|l|}{ Amiloride } \\
\hline Never used & $506(96.7)$ & $5134(98.2)$ & 1.0 & 1.0 \\
\hline Currently used & $9(1.7)$ & $53(1.0)$ & 1.8 & 1.5 (0.7 to 3.2) \\
\hline $\begin{array}{l}<0.5 \text { defined daily } \\
\text { dose }\end{array}$ & $1(0.2)$ & $9(0.2)$ & 1.1 & 1.2 (0.1 to 9.7) \\
\hline $\begin{array}{l}\geq 0.5 \text { defined daily } \\
\text { dose }\end{array}$ & $8(1.5)$ & $44(0.8)$ & 1.9 & $1.6(0.7$ to 3.4$)$ \\
\hline Used in the past & $8(1.5)$ & $43(0.8)$ & 2.0 & 1.9 (0.9 to 3.4$)$ \\
\hline
\end{tabular}

${ }^{*}$ For spironolactone: adjusted for ischaemic heart disease, history of gastric ulcer, heart failure, and use of angiotensin converting enzyme inhibitors, nitrates, platelet aggregation inhibitors, proton pump inhibitors or histamine 2 antagonists, anticoagulants, and other diuretics; for loop diuretics: adjusted for ischaemic heart disease, heart failure, and use of angiotensin converting enzyme inhibitors, nitrates, platelet aggregation inhibitors, proton pump inhibitors or histamine 2 antagonists, anticoagulants, calcium channel blockers, corticosteroids, and other diuretics; for amiloride: adjusted for stroke and use of calcium channel blockers, platelet aggregation inhibitors, antacids, nitrates, and other diuretics.
Table 3 Risk of upper gastrointestinal events according to use of spironolactone and loop diuretics in combination with ulcerogenic drugs. Values are number (\%) unless stated otherwise

\begin{tabular}{|c|c|c|c|c|}
\hline & $\begin{array}{l}\text { Cases } \\
(\mathrm{n}=523)\end{array}$ & $\begin{array}{l}\text { Controls } \\
(n=5230)\end{array}$ & Odds ratio & $\begin{array}{l}\text { Adjusted odds } \\
\text { ratio* }^{\star}(95 \% \mathrm{CI})\end{array}$ \\
\hline \multicolumn{5}{|l|}{ Spironolactone } \\
\hline $\begin{array}{l}\text { Never used spironolactone or an } \\
\text { ulcerogenic drug } \dagger\end{array}$ & $\begin{array}{c}188 \\
(35.9)\end{array}$ & $\begin{array}{l}2718 \\
(52.0)\end{array}$ & 1.0 & 1.0 \\
\hline $\begin{array}{l}\text { Currently using spironolactone and an } \\
\text { ulcerogenic drug }\end{array}$ & $9(1.7)$ & $17(0.3)$ & 10.0 & $\begin{array}{c}7.3 \\
\text { (2.9 to } 18.7)\end{array}$ \\
\hline $\begin{array}{l}\text { Currently using spironolactone but } \\
\text { not an ulcerogenic drug }\end{array}$ & $4(0.8)$ & $13(0.2)$ & 5.9 & $\begin{array}{c}3.7 \\
(1.1 \text { to } 13.1)\end{array}$ \\
\hline $\begin{array}{l}\text { Currently using an ulcerogenic drug } \\
\text { but not spironolactone }\end{array}$ & $\begin{array}{c}176 \\
(33.7)\end{array}$ & $\begin{array}{l}1024 \\
(19.6)\end{array}$ & 2.96 & $\begin{array}{c}2.47 \\
\text { (1.91 to } 3.19) \\
\end{array}$ \\
\hline Used spironolactone in the past & $2(0.4)$ & $14(0.3)$ & 2.7 & $\begin{array}{c}2.2 \\
(0.5 \text { to } 10.3)\end{array}$ \\
\hline Used an ulcerogenic drug in the past & $\begin{array}{c}144 \\
(27.5)\end{array}$ & $\begin{array}{l}1444 \\
(27.6)\end{array}$ & 1.59 & $\begin{array}{c}1.37 \\
(1.07 \text { to } 1.75)\end{array}$ \\
\hline \multicolumn{5}{|l|}{ Loop diuretics } \\
\hline $\begin{array}{l}\text { Never used loop diuretics or an } \\
\text { ulcerogenic drug }\end{array}$ & $\begin{array}{c}181 \\
(34.6)\end{array}$ & $\begin{array}{l}2678 \\
(51.2)\end{array}$ & 1.0 & 1.0 \\
\hline $\begin{array}{l}\text { Currently using loop diuretics and an } \\
\text { ulcerogenic drug } †\end{array}$ & $21(4.0)$ & $97(1.9)$ & 4.23 & $\begin{array}{c}2.75 \\
(1.50 \text { to } 5.04)\end{array}$ \\
\hline $\begin{array}{l}\text { Currently using loop diuretics but not } \\
\text { an ulcerogenic drug }\end{array}$ & $10(1.9)$ & $60(1.1)$ & 3.32 & $\begin{array}{c}2.24 \\
(1.04 \text { to } 4.81)\end{array}$ \\
\hline $\begin{array}{l}\text { Currently using an ulcerogenic drug } \\
\text { but not loop diuretics }\end{array}$ & $\begin{array}{c}164 \\
(31.4)\end{array}$ & $\begin{array}{c}944 \\
(18.0)\end{array}$ & 3.12 & $\begin{array}{c}2.52 \\
(1.94 \text { to } 3.28)\end{array}$ \\
\hline Used loop diuretics in the past & $14(2.7)$ & $\begin{array}{l}102 \\
(2.0)\end{array}$ & 2.74 & $\begin{array}{c}1.75 \\
(0.91 \text { to } 3.38)\end{array}$ \\
\hline Used ulcerogenic drugs in the past & $\begin{array}{c}133 \\
(25.4)\end{array}$ & $\begin{array}{l}1349 \\
(25.8)\end{array}$ & 1.60 & $\begin{array}{c}1.39 \\
(1.08 \text { to } 1.79)\end{array}$ \\
\hline
\end{tabular}

* For spironolactone: adjusted for gastric ulcer, oesophagitis, heart failure, and ischaemic heart disease, and use of angiotensin converting enzyme inhibitors, nitrates, proton pump inhibitors or histamine 2 inhibitors, and other diuretics; for loop diuretics: adjusted for ischaemic heart disease, heart failure, and use of calcium channel blockers, angiotensin converting enzyme inhibitors, nitrates, proton pump inhibitors or histamine 2 inhibitors, and other diuretics.

†Ulcerogenic drugs are non-steroidal anti-inflammatory drugs, platelet aggregation inhibitors, corticosteroids, and anticoagulants.

Finally, on the basis of an incidence rate of upper gastrointestinal events of 25.9 per 10000 person years among the exposed source population and 9.6 per 10000 person years among the unexposed source population, we calculated a population attributable risk of $9.3 / 10^{6} /$ year. Using demographic data from the Dutch Central Bureau of Statistics and on the basis of an overall incidence rate of upper gastrointestinal events of 9.7 per 10000 person years, we calculated that $1 \%$ of upper gastrointestinal events in 2000 could be attributed to the current use of spironolactone.

\section{Discussion}

Spironolactone was associated with an increased risk of upper gastrointestinal events. This association was stronger as the dosage increased and was most pronounced when spironolactone was combined with ulcerogenic drugs.

\section{Possible mechanism of action}

Aldosterone promotes the formation of fibrous tissue in the heart and in various other organs by binding to mineralocorticosteroid receptors; the effect is modulated by $11 \beta$ hydroxysteroid dehydrogenase enzymes. ${ }^{14}$ Compounds with mineralocorticosteroid-like activity also promote tissue repair, whereas spironolactone inhibits the formation of fibrous tissue. $^{6}{ }^{14}{ }^{15}$ This inhibition is beneficial in patients with heart failure and arterial hypertension, as it prevents cardiac fibrosis. ${ }^{15-17}$ The stomach, and to a lesser extent, the duodenum express mineralocorticosteroid receptors and $11 \beta$ hydroxysteroid dehydrogenase enzymes, so fibrous tissue formation-via binding of 
aldosterone to the mineralocorticosteroid receptors-is probably important in the healing of gastric or duodenal erosions and ulcers. ${ }^{18}$ Thus, aldosterone receptor antagonists, such as spironolactone, could impair the healing of gastric or duodenal erosions and result in the formation of gastroduodenal ulcers, with or without bleeding. This could explain why the association between current use of spironolactone and upper gastrointestinal events is highest in patients also taking an ulcerogenic drug.

\section{Strengths and limitations of our study}

Our study had a population based design, so selection bias is unlikely as all cases and controls came from the same source population. Information bias is also unlikely, as data were gathered prospectively without knowledge of the hypothesis studied. Misclassification of the outcome is probably minimal as we manually validated all cases and only analysed definite cases, doctors who classified cases were blinded to the patient's drug exposure, and known risk factors for upper gastrointestinal events appeared as risk factors in our analysis as well. To control for confounding by indication we adjusted for heart failure, as one study identified heart failure as a risk factor for bleeding of peptic ulcers. ${ }^{3}$ The authors of that study used patients' self reports and the concurrent use of diuretics and digoxin to define heart failure. The association between the different diuretics and outcome was not studied separately, and part of the association might be explained by the current use of spironolactone.

Confounding by severity is also possible. Patients with more severe heart failure are more likely to be treated with spironolactone than those with less severe disease, but they might also have an inherently higher risk of upper gastrointestinal events. Increasing dosages of loop diuretics, however, were not associated with increased risk of upper gastrointestinal events, but a strong dose-response relation was seen for increasing dosages of spironolactone. Thus, confounding by severity appears unlikely. In contrast to a previous study, we found no association or dose relation between amiloride and upper gastrointestinal events. ${ }^{7}$ However, in the earlier study patients were given $15 \mathrm{mg}$ amiloride each day, whereas none of the patients in our study received more than $5 \mathrm{mg}$ daily.

\section{Conclusions}

A Canadian study reported a large increase in prescriptions for spironolactone after publication of the randomised aldactone evaluation study, which showed that spironolactone significantly improves outcomes in patients with severe heart failure. ${ }^{19}$ We also found such an increase. On the basis of these observations, we believe doctors and patients should be informed about the potential of upper gastrointestinal events when using spironolactone. Spironolactone reduces mortality in patients with symptomatic heart failure, and doctors should not refrain from using this drug in the treatment of these patients. However, we advise caution and careful follow-up when prescribing spironolactone to patients at risk of upper gastrointestinal events.

Contributors: All authors helped conceive the idea for the study, design the study, and analyse and interpret the data. KMCV and MCJMS drafted the manuscript.JPD, BHChS, and MCJMS revised the manuscript and provided statistical expertise. MCJMS supervised the study. MCJMS is guarantor. Funding: None.

Competing interests: None declared by KMCV, GM, JPD, and BHChS. MCJMS is leader of the IPCI database, a general practice database used for research by pharmaceutical companies. She has received several research grants in cardiovascular disease from Pfizer (license holder of Aldactone), but none was related to the topic of this paper. She has also received travel reimbursement from Pfizer for participation in conferences.
Ethical approval: internal review board of the integrated primary care information project database.

1 Rollhauser C, Fleischer DE. Nonvariceal upper gastrointestinal bleeding. Endoscopy 2004;36:52-8

2 Hernandez-Diaz S, Rodriguez LA. Association between nonsteroidal antiinflammatory drugs and upper gastrointestinal tract bleeding/perforation: an overview of epidemiologic studies published in the 1990s. Arch Intern Med 2000;160:2093-9.

3 Weil J, Langman MJ, Wainwright P, Lawson DH, Rawlins M, Logan RF, et al. Peptic ulcer bleeding: accessory risk factors and interactions with non-steroidal anti-inflammatory bleeding: accessory risk factor
drugs. Gut 2000;46:27-31.

4 Mackay A, Stevenson RD. Gastric ulceration induced by spironolactone. Lancet 1977;1(8009):481.

Kremer D, Fraser R, Brown JJ, Lever AF, Davies DL, Robertson JI. Amiloride in primary hyperaldosteronism with chronic peptic ulceration. BMJ 1973;2:216-7.

6 Doll R, Langman MJ, Shawdon HH. Treatment of gastric ulcer with carbenoxolone: antagonistic effect of spironolactone. Gut 1968;9:42-5.

7 Reed PI, Lewis SI, Vincent-Brown A, Holdstock DJ, Gribble RJ, Murgatroyd RE, et al. The influence of amiloride on the therapeutic and metabolic effects of carbenoxolone in patients with gastric ulcer. A double-blind controlled trial. Scand J Gastroenterol Suppl 1980;65:51-7.

8 Schrijvers A. Health and health care in the Netherlands: a critical self-assessment of Dutch experts in medical and health sciences. Utrecht: De Tijdstroom, 1997.

9 Lamberts $\mathrm{H}$, Wood M, Hofmans-Okkes IM. International primary care classifications: the effect of fifteen years of evolution. Fam Pract 1992;9:330-9.

10 van der Lei J, Duisterhout JS, Westerhof HP, van der Does E, Cromme PV, Boon WM, et al. The introduction of computer-based patient records in the Netherlands. Ann Intern Med 1993;119:1036-41

11 Anonymous. ATC and DDD values. Geneva: World Health Organization, 1996

12 Vlug AE, van der Lei J, Mosseveld BM, van Wijk MA, van der Linden PD, Sturkenboom MC, et al. Postmarketing surveillance based on electronic patient records: the IPCI project. Methods Inf Med 1999;38:339-44.

13 Hennekens C, Buring J. Epidemiology in medicine. Boston/Toronto: Little Brown, 1987.

14 Slight SH, Chilakamarri VK, Nasr S, Dhalla AK, Ramires FJ, Sun Y, et al. Inhibition of tissue repair by spironolactone: role of mineralocorticoids in fibrous tissue formation. Mol Cell Biochem 1998;189:47-54

15 Lijnen P, Petrov V. Induction of cardiac fibrosis by aldosterone. J Mol Cell Cardiol 2000;32:865-79.

16 Pitt B, Zannad F, Remme WJ, Cody R, Castaigne A, Perez A, et al. The effect of spironolactone on morbidity and mortality in patients with severe heart failure. Randomized aldactone evaluation study investigators. N Engl J Med 1999;341:709-17.

17 Pitt B, White H, Nicolau J, Martinez F, Gheorghiade M, Aschermann M, et al. Eplerenone reduces mortality 30 days after randomization following acute myocardial infarction in patients with left ventricular systolic dysfunction and heart failure. $J \mathrm{Am}$ Coll Cardiol 2005;46:425-31.

18 Kato K, Sasano H, Ohara S, Sekine H, Mochizuki S, Mune T, et al. Coexpression of mineralocorticoid receptors and 11beta-hydroxysteroid dehydrogenase 2 in human gastric mucosa. J Clin Endocrinol Metab 1999;84:2568-73.

19 Juurlink DN, Mamdani MM, Lee DS, Kopp A, Austin PC, Laupacis A, et al. Rates of Juurlink DN, Mamdani MM, Lee DS, Kopp A, Austin PC, Laupacis A, et al. Rates of
hyperkalemia after publication of the randomized aldactone evaluation study. $N$ EnglJ Med 2004;351:543-51.

(Accepted 26 May 2006)

doi $10.1136 /$ bmj.38883.479549.2F

Department of Medical Informatics, Erasmus MC, PO Box 1738, 3000 Rotterdam, Netherlands

Katia Verhamme senior researcher

Georgio Mosis research fellow

Jeanne Dieleman senior researcher

Miriam Sturkenboom associate professor of pharmacoepidemiology

Department of Epidemiology and Biostatistics, Erasmus MC

Bruno Stricker professor of pharmacoepidemiology

Correspondence to: K Verhamme k.verhamme@erasmusmc.nl

\section{What is already known on this topic}

Individual case reports indicate an association between spironolactone and upper gastrointestinal events

\section{What this study adds}

This population based, case-control study found that spironolactone was associated with a 2.7 -fold increased risk of upper gastrointestinal events (bleeding or ulcers)

The association increased proportionally with dosage and was most pronounced when combined with ulcerogenic drugs 